\title{
Management of Ponatinib in Patients with Chronic Myeloid Leukemia with Cardiovascular Risk Factors
}

\author{
Marco Santoro $^{a}$ Vincenzo Accurso $^{\text {b }}$ Salvatrice Mancuso ${ }^{b}$ \\ Angelo Davide Contrino ${ }^{b}$ Mariano Sardo $^{b}$ Giuseppina Novo ${ }^{d}$ \\ Florinda Di Piazza ${ }^{c}$ Alessandro Perez ${ }^{c}$ Antonio Russo ${ }^{c}$ Sergio Siragusa ${ }^{b}$

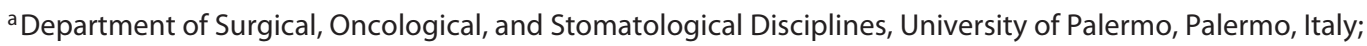 \\ ${ }^{\mathrm{b}}$ Hematology Division, University Hospital Policlinico "Paolo Giaccone", Palermo, Italy; ' Department of Surgical, \\ Oncological, and Stomatological Disciplines, Section of Medical Oncology, University of Palermo, Palermo, Italy; \\ ${ }^{\mathrm{d}}$ Department of Cardiology, University Hospital Policlinico "Paolo Giaccone", Palermo, Italy
}

\section{Keywords}

Ponatinib · Cardiovascular risk · Chronic myeloid leukemia

\section{Abstract}

Cardiovascular (CV) adverse events are considered common complications of ponatinib treatment. Recently, it has been demonstrated that ponatinib dose reductions in definite settings can obtain optimal responses and lower ponatinib-related CV events. In this study, we describe the management of 5 patients with chronic myeloid leukemia treated with ponatinib, from second to fourth line of tyrosine kinase inhibitor therapy, carrying high pre-ponatinib CV risk, who obtained optimal molecular response and developed no CV adverse event during follow-up. Among these 5 patients, 2 had diagnosis of ischemic heart disease and underwent percutaneous angioplasty, 2 had type 2 diabetes and arterial hypertension, and 1 had only arterial hypertension. Median followup for ponatinib therapy is 1,039 days (34.6 months). Median dosage administered is $30 \mathrm{mg}$ a day. SCORE charts were used to estimate risk of $\mathrm{CV}$ death in 10 years and Charlson Comorbidity Index was applied to estimate age-adjusted risk of death related to comorbidities. Strict cardiologic follow-up (complete evaluation every 3 to 6 months) and maximum effort in the control of $\mathrm{CV}$ modifiable risk factors are strongly recommended in the management of ponatinib treatment in patients at high risk for CV events and may allow the use of ponatinib in patients belonging to CV risk category.

(c) 2019 S. Karger AG, Basel

\section{Background}

Ponatinib is a third-generation tyrosine kinase inhibitor (TKI) indicated in adult patients with diagnosis of chronic myeloid leukemia (CML) who are resistant to dasatinib or nilotinib or who have the T315I mutation. Clinical studies have been conducted on a population of patients who had already underwent at least two other TKIs and demonstrated high efficacy and acceptable toxicity profile $[1,2]$.

Cardiovascular (CV) adverse events (AEs) are considered common complications of ponatinib treatment. Commonly, pre-existing CV risk factors or $\mathrm{CV}$ events in

\section{KARGER}

(C) 2019 S. Karger AG, Basel

karger@karger.com

www.karger.com/che
Marco Santoro

Department of Surgical, Oncological, and Stomatological Disciplines

University of Palermo, Via del Vespro 129

IT-90127 Palermo (Italy)

E-Mail marco.santoro03@unipa.it 
Table 1. Age, CCI, SCORE pre-ponatinib (pre-Pona), and ponatinib (Pona) treatment data of the 5 patients presented in the text

\begin{tabular}{lllllllll}
\hline No. TKI & $\begin{array}{l}\text { Age at } \\
\text { Pona }\end{array}$ & $\begin{array}{l}\text { Median Pona } \\
\text { dose, mg/day }\end{array}$ & $\begin{array}{l}\text { CCI 10- } \\
\text { year risk }\end{array}$ & $\begin{array}{l}\text { SCORE } \\
\text { pre-Pona }\end{array}$ & $\begin{array}{l}\text { Best MR } \\
\text { Pona }\end{array}$ & $\begin{array}{l}\text { non-CV AE } \\
\text { Pona exp., Follow-up, } \\
\text { months }\end{array}$ & $\begin{array}{l}\text { months } \\
\text { month }\end{array}$ \\
\hline 1 & 3 & 53 & 30 & $21 \%$ & $10 \%$ & MR3 & abdominal cramps & 4 \\
2 & 2 & 72 & 20 & $21 \%$ & $15 \%$ & MR3 & high lipase levels & 44 \\
3 & 3 & 61 & 16.5 & $0 \%$ & $5 \%$ & MR3 & & 44 \\
4 & 4 & 68 & 18 & $53 \%$ & $7 \%$ & MR3 & & 34 \\
5 & 4 & 46 & 20 & $90 \%$ & $2 \%$ & MR4 & erectile deficit, high lipase levels & 28 \\
\hline
\end{tabular}

patients with CML usually prevent the clinicians in prescribing ponatinib, even when it would be the best choice in terms of expected efficacy. The phase II PACE trial highlighted the risk for arterial occlusive disease and CV AEs in general in patients treated with ponatinib. The drug was temporarily suspended from commerce by US FDA and reintroduced when analysis on CV risk factors in patients who developed CV complications was completed and demonstrated that those occurred mostly in patients with pre-ponatinib high CV risk [3]. Cardiovascular assessment, accurate control, and improvement of modifiable CV risk factors are recommended in patients eligible to ponatinib treatment [4]. The Systemic Coronary Risk Evaluation (SCORE) charts are a useful tool validated in estimating $\mathrm{CV}$ risk of death at 10 years and take into account these variables: age, gender, smoking status, systolic blood pressure (SBP), total cholesterol levels, high-/low-risk countries [5-7]. The SCORE charts have been used to predict the risk of developing a $\mathrm{CV} \mathrm{AE}$ in patients undergoing ponatinib treatment [8]. Recently, international guidelines for $\mathrm{CV}$ disease prevention were published and the SCORE charts were judged easy-to-use for a rapid evaluation of the patients' risk, but not extensively applicable (age 40-65 years) and giving limited information (only estimation of fatal CV events). For patients with diagnosis of diabetes mellitus, renal failure, or $\mathrm{CV}$ diseases, the use of modified scores is recommended by the same guidelines [9].

Recently, it has been demonstrated that ponatinib dose reductions in definite settings can obtain optimal responses and lower ponatinib-related CV AEs. Pharmacokinetic analysis has indicated the possibility of reducing the starting dose of ponatinib to $15 \mathrm{mg}$ /day and preliminary data showed advantages in terms of safety while maintaining its efficacy [10].

In this study, we describe the management of 5 patients with CML treated with ponatinib, from second to fourth line of TKI therapy and carrying pre-ponatinib
$\mathrm{CV}$ risk, who obtained optimal molecular response and developed no CV AEs during or after ponatinib treatment.

\section{Patients and Methods}

In our center, 5 patients with history of $\mathrm{CV}$ risk or $\mathrm{CV}$ disease were treated with ponatinib in at least second line of TKI therapy for CML, with first dose of ponatinib prescribed between May 2015 and April 2018. Among these 5 patients, 2 had diagnosis of ischemic heart disease and underwent percutaneous angioplasty, 2 had type 2 diabetes and arterial hypertension, and 1 had only arterial hypertension. Median follow-up for ponatinib therapy is 1,039 days (34.6 months). Median dosage administered is $30 \mathrm{mg} \mathrm{a}$ day. For all the 5 patients, stable or improved molecular response was registered during ponatinib treatment, with respect to the one they had before. Three of five patients are still in treatment with ponatinib.

Pre-ponatinib CV risk at 10 years was estimated applying the SCORE charts. The Charlson Comorbidity Index (CCI) was used to determine impact of comorbidities before ponatinib. CCI was applied in CML and demonstrated affordability in the estimation of prognosis [11-13].

\section{Reports}

We here report brief descriptions of the management of patients with pre-ponatinib CV risk. Median follow-up is 37 months starting from first ponatinib dose. Data exposed in the following descriptions are reported in Table 1 for better visualization.

\section{Patient 1}

Patient 1 is a 47 -year-old male who started ponatinib when he was 53 as the third-line therapy of CP-CML, being dasatinib intolerant (relapsing pleural effusion). Dasatinib was the second-line TKI, after imatinib first line. Imatinib was stopped 3 months after the beginning of the therapy because of muscle cramps, diffuse edema, and increased amylase and lipase levels. At that time, partial cytogenetic response was achieved. Dasatinib second line was withdrawn in October 2016 because of relapsing pleural effusion. Dasatinib dose has been gradually decreased to $50 \mathrm{mg}$ every other day, without benefit on toxicity, before deciding for drug with- 
drawal. At the time of dasatinib withdrawal, molecular evaluation revealed MR2. Before ponatinib first dose, comorbidities were arterial hypertension, diabetes mellitus type 2 , and chronic HCV infection, accounting for a CCI of 5 (21\% 10-year estimated survival). CV risk SCORE accounted for a 10\% risk, with SBP $150 \mathrm{~mm}$ $\mathrm{Hg}$, total cholesterol $270 \mathrm{mg} / \mathrm{dL}$, and smoke exposition positive. The patient was already taking low-dose aspirin (100 mg once a day). Initial dose was $45 \mathrm{mg}$ a day and dose reduction to $30 \mathrm{mg}$ and then to $15 \mathrm{mg}$ was prescribed due to a non-CV AE (abdominal cramps). Computed tomography scan and normal amylase and lipase levels excluded pancreatitis. Ponatinib was stopped after 3.8 months for persisting abdominal cramps, with resolution some days after withdrawal. Response evaluation revealed MR2.

\section{Patient 2}

Patient 2 received diagnosis of accelerated-phase CML at 71 years and started ponatinib 1 year later as a second-line TKI, for intolerance to dasatinib first line: three episodes of pleural effusion. Response to dasatinib at the moment of suspension was MR3. Comorbidities at first ponatinib dose were chronic obstructive pulmonary disease, arterial hypertension, and chronic HBV infection, with 5 points at CCI, meaning $21 \%$ expected survival at 10 years. CV SCORE accounted for 15\%, with SBP $120 \mathrm{~mm} \mathrm{Hg}$, total cholesterol $160 \mathrm{mg} / \mathrm{dL}$, and smoke exposition negative. Low-dose aspirin was prescribed in association with ponatinib. Initial ponatinib dose was $45 \mathrm{mg}$ a day, and dose reduction was prescribed to $30 \mathrm{mg}$ when MR3 was reached and then to $15 \mathrm{mg}$ a day when high lipase values occurred at control exams. Dose reduction obtained normalization of lipase and amylase values. No CV AEs were registered. The patient was still taking ponatinib at the dose of $15 \mathrm{mg}$ a day at checkpoint date.

\section{Patient 3}

Diagnosis of CP-CML occurred at 52 and third-line therapy with ponatinib was prescribed for resistance to second-line dasatinib therapy (no ABL domain mutations revealed) at 61 years of age, when molecular response was MR3. First-line TKI was imatinib, which was withdrawn because of resistance (confirmed loss of MR3), with no demonstration of ABL domain mutations. Preponatinib comorbidities were arterial hypertension, type 2 diabetes mellitus, and active metastatic breast cancer receiving chemotherapy. CCI accounted to 9 , with $0 \%$ expected survival at 10 years. The CV SCORE revealed 5\% possibility of CV death in the next 10 years, with SBP $150 \mathrm{~mm} \mathrm{Hg}$, total cholesterol $200 \mathrm{mg} / \mathrm{dL}$, and smoke exposition positive, but actual CV risk was surely higher considering active breast cancer and chemotherapy. Low-dose aspirin was prescribed in association with ponatinib, according to the high CV risk. During ponatinib treatment, atrial fibrillation was diagnosed and the patient started anticoagulant therapy with low-molecular-weight heparin. Aspirin prophylaxis was not withdrawn. Initial dose of ponatinib was $30 \mathrm{mg}$, which was reduced to $15 \mathrm{mg}$ when MR3 was reached. The patient was still taking ponatinib at the dose of $15 \mathrm{mg}$ a day at checkpoint.

\section{Patient 4}

Patient 4 was 59-year-old at CP-CML diagnosis and started ponatinib when he was 68 , as the fifth-line therapy, being considered intolerant to all other TKIs. Comorbidities at ponatinib first dose were hypertensive-ischemic chronic heart disease with stable angina and abdominal aorta aneurysm. A CCI of 4 points revealed a 53\% probability of survival at 10 years. The SCORE accounted for 7\% risk, with SBP $140 \mathrm{~mm} \mathrm{Hg}$, total cholesterol $190 \mathrm{mg} / \mathrm{dL}$, and the absence of smoke exposition. The patient was already assuming antiplatelet therapy at the time of ponatinib first dose. In spite of the high CV risk, ponatinib was the only possible choice for this patient. Start dose was $30 \mathrm{mg}$ and reduction to $15 \mathrm{mg}$ a day was applied when MR3 was reached, 2 months after the first dose. The patient was still taking ponatinib at the dose of $15 \mathrm{mg}$ a day at checkpoint. No CV AEs were registered during ponatinib treatment.

\section{Patient 5}

Patient 5 was diagnosed with CP-CML when he was 39 years old and switched from third-line dasatinib to ponatinib because of dasatinib intolerance (persistent elevated lipase and amylase levels also after dose reductions). CCI at ponatinib first dose was 2 , with a $90 \%$ probability of survival at 10 years. Pre-ponatinib SCORE was $1 \%$, but it was considered not affordable, due to preexistent diagnosis of chronic heart disease (STEMI during nilotinib). The patient was already assuming low-dose aspirin at first dose. Start dose was $30 \mathrm{mg}$ a day, reduced to $15 \mathrm{mg}$ a day for non-CV AEs (erectile deficit and high lipase levels). Doppler evaluation excluded a vascular cause for erectile deficit and the patient was addressed to endocrine evaluation. The patient stopped ponatinib treatment for persistence of high lipase levels after 28.5 months of treatment, having reached MR4, and started off-therapy monthly follow-up.

\section{Discussion}

No CV AE was reported for any of these 5 patients recently treated in our center and bearing pre-ponatinib $\mathrm{CV}$ risk factors. Strict cardiologic control was operated during ponatinib therapy. For this purpose, these patients have been followed by cardio-oncologic specialists, who are confident with hematological medications and sensible to evaluate TKIs adjunctive CV risk in modulating cardiologic treatments. All the patients had been evaluated every 6 months at cardio-oncology unit with visit, electrocardiogram, and echocardiography, and the riskbenefit of TKI therapy was collegially debated. CV therapies were optimized and maximum effort was put into counselling for lifestyle adjustments to reduce the weight of modifiable CV factors on global risk.

The median SCORE accounted for $7 \%$ among these 5 patients, but this value has to be considered as underestimated because it does not consider history of chronic heart disease ( 2 patients) and age over 65 years ( 2 other patient). The use of the SCORE can be useful and quick to assess when evaluating the CV global risk of a patient who has to be treated with drugs that can have an impact on the risk itself, but it is only validated for primary prevention. Moreover, it was not validated in large cohorts of patients with diagnosis of CML assuming TKIs with 
known associated CV risk. Median CCI score was 5, meaning a $21 \%$ probability of survival at 10 years. Taking into account chronic and acute heart diseases and other CV disease history, we think that CCI has to be used in association with the SCORE charts to better estimate CV and overall prognosis in this kind of patients.

Median ponatinib duration of therapy was 34.6 months between the 5 patients described, of which $3 / 5$ were still taking ponatinib at checkpoint. Ponatinib dose was reduced in all of the 5 patients with CV risk at our center and lower affordable dose was prescribed and maintained with target molecular response at least MR3. None of the 5 patients lost molecular response during ponatinib, in spite of dose reduction.

Exception made for patient 1, who stopped ponatinib due to a non-CV AE (abdominal cramps), the drug was well tolerated and dose reduction allowed long duration of treatment, with a median ponatinib treatment length of 34.6 months. Ponatinib withdrawal occurred in patient 5 too, due to high lipase and amylase levels after 28 months of treatment, and he is now in off-therapy follow-up.

\section{Conclusions}

Cardiovascular comorbidities are often present at diagnosis in CML, due to the similar median age of onset of both diseases and of global frequency of CV diseases. CV risk factors in absence of overt disease are even more prevalent in the general population.

The SCORE charts can be used, but they are probably not affordable enough to estimate CV risk in CML patients who have to assume TKIs that carry adjunctive CV risk. Other scores have to be validated in a large cohort of CML patients assuming TKIs. Using CCI in association with SCORE charts and/or with other risk scores may help in better define CV and overall risk of death and of $\mathrm{CV}$ non-fatal events in patients eligible to ponatinib and other TKIs.

The presence of a moderate to high CV risk is commonly considered a contraindication to prescribe ponatinib as a therapy of choice in CML even in cases in which other TKIs available do not seem to assure the same efficacy. In the cases we described, 5 patients with $\mathrm{CV}$ risk factors and/or chronic heart disease, no CV AEs was registered with a median follow-up of 37 months. All of the 5 patients started with a dose between 45 and $30 \mathrm{mg}$ a day and then passed to the lower dose of $15 \mathrm{mg}$ a day. Dose reduction probably reduced TKI-related CV risk and maintained efficacy on molecular response, though.
Strict cardiologic follow-up (complete evaluation every 3 to 6 months) and maximum effort in the control of $\mathrm{CV}$ modifiable risk factors are strongly recommended in the management of ponatinib treatment in patients at high risk for $\mathrm{CV}$ events.

\section{Statement of Ethics}

This study was approved by our local ethics committee and consent for data collection and publication was obtained from the patients involved in the study.

\section{Disclosure Statement}

The authors declare that they have no competing interests.

\section{Funding Sources}

No funding sources have to be declared.

\section{Availability of Data and Material}

The datasets generated and/or analyzed during the current study are not publicly available due to privacy laws but are available from the corresponding author on reasonable request.

\section{Author Contributions}

M.S.: data collection, writing, and editing; V.A.: data collection and elaboration; A.D.C.: data collection; M.S.: data collection; G.N.: data collection and elaboration; F.D.P.: data collection and revision; A.P.: data collection; A.R.: revision; S.S.: revision and editing.

References

1 Massaro F, Molica M, Breccia M. Ponatinib: A Review of Efficacy and Safety. Curr Cancer Drug Targets. 2018;18(9):847-56.

2 Cortes JE, Kim DW, Pinilla-Ibarz J, le Coutre PD, Paquette R, Chuah C, Nicolini FE, Apperley JF, Khoury HJ, Talpaz M, DeAngelo DJ, Abruzzese E, Rea D, Baccarani M, Müller MC, Gambacorti-Passerini C, Lustgarten S, Rivera VM, Haluska FG, Guilhot F, Deininger MW, Hochhaus A, Hughes TP, Shah NP, Kantarjian HM. Ponatinib efficacy and safety in Philadelphia chromosome-positive leukemia: final 5-year results of the phase 2 PACE trial. Blood. 2018 Jul 26;132(4):393-404. 
3 Valent P, Hadzijusufovic E, Hoermann G, Füreder W, Schernthaner GH, Sperr WR, Kirchmair R, Wolf D. Risk factors and mechanisms contributing to TKI-induced vascular events in patients with CML. Leuk Res. 2017 Aug;59:47-54.

4 Jain P, Kantarjian H, Boddu PC, NoguerasGonzález GM, Verstovsek S, Garcia-Manero G, Borthakur G, Sasaki K, Kadia TM, Sam P, Ahaneku H, O'Brien S, Estrov Z, Ravandi F, Jabbour E, Cortes JE. Analysis of cardiovascular and atherothrombotic adverse events in chronic-phase CML patients after frontline TKIs. Blood Adv. 2019 Mar 26;3(6):851-61.

5 Conroy RM, Pyörälä K, Fitzgerald AP, Sans S, Menotti A, De Backer G, De Bacquer D, Ducimetière $P$, Jousilahti $P$, Keil U, Njølstad I, Oganov RG, Thomsen T, Tunstall-Pedoe H, Tverdal A, Wedel H, Whincup P, Wilhelmsen L, Graham IM; SCORE project group. Estimation of ten-year risk of fatal cardiovascular disease in Europe: the SCORE project. Eur Heart J. 2003 Jun;24(11):987-1003.

6 D'Agostino RB Sr, Vasan RS, Pencina MJ, Wolf PA, Cobain M, Massaro JM, Kannel WB. General cardiovascular risk profile for use in primary care: the Framingham Heart Study. Circulation. 2008 Feb 12;117(6):74353.

7 Mahmood SS, Levy D, Vasan RS, Wang TJ. The Framingham Heart Study and the Epide- miology of Cardiovascular Diseases: A Historical Perspective. Lancet. 2014 Mar 15; 383(9921):999-1008.

8 Caocci G, Mulas O, Abruzzese E, Luciano L, Iurlo A, Attolico I, Castagnetti F, Galimberti S, Sgherza N, Bonifacio M, Annunziata M, Gozzini A, Orlandi EM, Stagno F, Binotto G, Pregno P, Fozza C, Trawinska MM, De Gregorio F, Cattaneo D, Albano F, Gugliotta G, Baratè C, Scaffidi L, Elena C, Pirillo F, Scalzulli E, La Nasa G, Foà R, Breccia M. Arterial occlusive events in chronic myeloid leukemia patients treated with ponatinib in the real-life practice are predicted by the Systematic Coronary Risk Evaluation (SCORE) chart. Hematol Oncol. 2019 Aug;37(3):296-302.

9 Piepoli MF, Hoes AW, Agewall S, Albus C, Brotons C, Catapano AL, Cooney MT, Corrà $U$, Cosyns $B$, Deaton $C$, Graham I, Hall MS, Hobbs FDR, Løchen ML, Löllgen $\mathrm{H}$, Marques-Vidal P, Perk J, Prescott E, Redon J, Richter DJ, Sattar N, Smulders Y, Tiberi $M$, van der Worp HB, van Dis I, Verschuren WMM, Binno S; ESC Scientific Document Group. 2016 European Guidelines on cardiovascular disease prevention in clinical practice. Eur Heart J. 2016 Aug 1;37(29): 2315-81.

10 Molica M, Scalzulli E, Colafigli G, Foà R, Breccia M. Insights into the optimal use of ponatinib in patients with chronic phase chronic myeloid leukaemia. Ther Adv Hematol. 2019 Mar 1;10:2040620719826444.

11 Saussele S, Krauss MP, Hehlmann R, Lauseker M, Proetel U, Kalmanti L, Hanfstein B, Fabarius A, Kraemer D, Berdel WE, Bentz M, Staib P, de Wit M, Wernli M, Zettl F, Hebart HF, Hahn M, Heymanns J, Schmidt-Wolf I, Schmitz N, Eckart MJ, Gassmann W, Bartholomäus A, Pezzutto A, Leibundgut EO, Heim D, Krause SW, Burchert A, Hofmann WK, Hasford J, Hochhaus A, Pfirrmann M, Müller MC; Schweizerische Arbeitsgemeinschaft für Klinische Krebsforschung and the German CML Study Group. Impact of comorbidities on overall survival in patients with chronic myeloid leukemia: results of the randomized CML study IV. Blood. 2015 Jul 2; 126(1):42-9.

12 Uemura M, Imataki O, Kawachi Y, Kawakami K, Hoshijima Y, Matsuoka A, Kadowaki N. Charlson comorbidity index predicts poor outcome in CML patients treated with tyrosine kinase inhibitor. Int J Hematol. 2016 Nov; 104(5):621-27.

13 Breccia M, Molica M, Colafigli G, Zacheo I, Latagliata R, Tafuri A, Alimena G. Correlation between Charlson comorbidity index and outcome in patients with chronic phase chronic myeloid leukemia treated with second-generation tyrosine kinase inhibitors upfront. Leuk Lymphoma. 2015 Jul;56(7):2206-7. 